\title{
CARTOGRAFIA DAS BACIAS HIDROGEOLÓGICAS USANDO OS MÉTODOS POTENCIOMÉTRICO E GRAVIMÉTRICO - NORDESTE DO ESTADO DO PARÁ -
}

\author{
Araújo, Paulo Pontes ${ }^{1}$; Freddo, V.J.F.'; Ferreira, H.S ${ }^{3} \&$ Abreu, F. A. M. de ${ }^{4}$
}

\begin{abstract}
Resumo - Na região nordeste do Pará, entre os meridianos $48^{\circ} 15^{\prime} 20^{\prime \prime}$ WGr a 46³8'25" WGr e paralelos $0^{\circ} 35^{\prime} 11^{\prime}$ 'S a 0125'32" S, residem 3,7 milhões de habitantes (IBGE, 2014), e nela predomina o déficit de água para uso humano, em área urbana e rural. Utilizando-se dos métodos potenciométrico e gravimétrico, com suporte de SIG, buscou-se definir as bacias hidrogeológicas do aquífero livre Barreiras e estabelecer correlações com as bacias hidrográficas presentes nessa região. O mapa potenciométrico foi elaborado a partir de 576 poços cadastrados pelo Projeto SIAGAS, da CPRM e o mapa gravimétrico extraído do Projeto Geologia e Recursos Minerais do Estado do Pará (CPRM, 2008). Os resultados obtidos da interpolação, entre o mapa potenciométrico e o gravimétrico, mostram a posição dos divisores hidrogeológicos. Observou-se que ocorre concordância entre o divisor da bacia hidrográfica e o da bacia hidrogeológica, com exceção de duas pequenas áreas, destacadas no mapa de bacias hidrogeológicas, nas quais o fluxo das águas subterrâneas rasas não acompanha as configurações da superfície do terreno, ultrapassando divisores topográficos e os limites das bacias hidrográficas. A esta discordância entre os divisores das bacias hidrográficas e hidrogeológicas atribuem-se variações litológicas, condicionantes tectônicos ou até a presença de rocha cárstica, próxima a superfície.
\end{abstract}

Palavras-Chave: bacia hidrogeológica; método potenciométrico; método gravimétrico.

Abstract - In the northeastern region of Pará, between the meridians $48^{\circ} 15^{\prime} 20^{\prime \prime}$ WGR the $46^{\circ} 38^{\prime} 25^{\prime \prime}$ WGR and parallel $0^{\circ} 35^{\prime} 11^{\prime \prime} \mathrm{S}$ to $01^{\circ} 25^{\prime} 32^{\prime} \mathrm{S}$, live 3.7 million inhabitants (IBGE, 2014), and it prevails the deficit water for human use in urban and rural areas. Using the potentiometric and gravimetric methods with GIS support, sought to define the hydrogeological basins of unconfined aquifer Barriers and establish correlations with the present river basins in the region. The potentiometric map was drawn from 576 registered wells at SIAGAS Project (CPRM), and extracted gravimetric map the Geology and Resources of the State of Pará Minerals Project (CPRM, 2008). The result of correlation between the map potentiometric and the gravimetric shows the hydrogeological dividers position. It was observed that occurs agreement between the divider of the hydrographic basin and the hydrogeological basin, except for two small areas highlighted in the map of hydrogeological basins, where the flow of shallow groundwater does not follow the ground surface settings, surpassing topographic splitters and watershed. To this disagreement between the divisors of river and hydrogeological basins are attributed to lithological variations, tectonic conditions or even the presence of karst rock near the surface.

Keywords: hydrogeologic basin; potenciometric method; gravimetric method

\footnotetext{
1, 2 e 3 Serviço Geológico do Brasil-CPRM; Av. Dr. Freitas, 3645, Belém-PA, (091) 3182.1318, paulo.araujo@cprm.gov.br; valmor.freddo@cprm.gov.br; hugo.ferreira@cprm.gov.br;

${ }^{4}$ Universidade Federal do Pará; Av. Tancredo Neves s/n; Belém-PA, (091) 3201.8185, famatos@ufpa.br
} 


\section{INTRODUÇÃO}

Os estudos geocientíficos até então realizados na região nordeste do Pará tem contribuído significativamente para o avanço do conhecimento hidrogeológico, com destaque para a Região de Belém e para as sedes municipais como Santa Isabel do Pará, Bujaru, Santo Antônio do Tauá, Castanhal, Capanema, Santo Antônio do Tauá, Capitão Poço, Primavera, Santa Luzia do Pará, Vigia, Ourém e Salinópolis. A região estudada concentra 3,7 milhões de habitantes (IBGE, 2014), o que representa mais da metade da população do Estado do Pará (Figura 1).

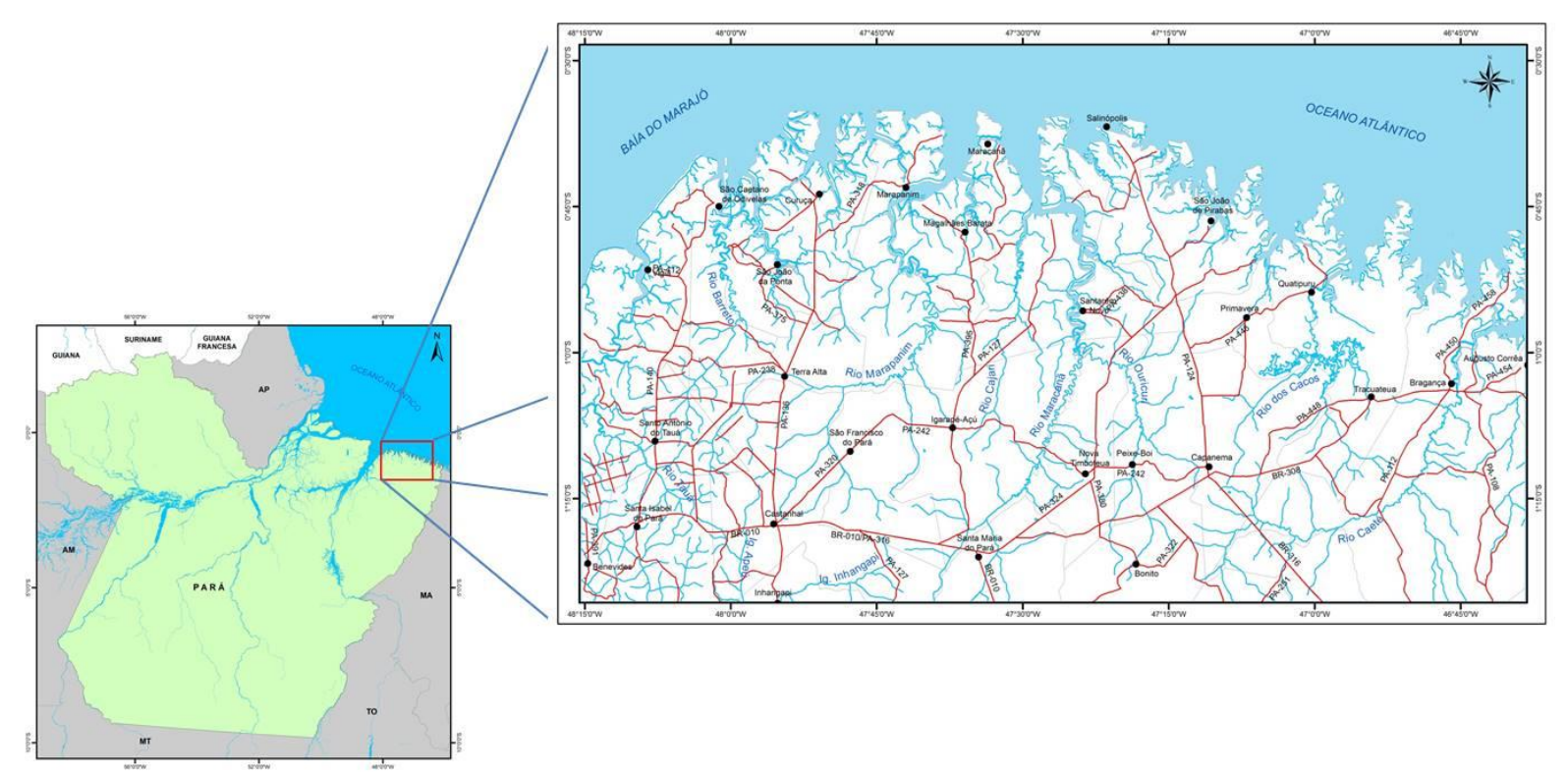

Figura 1. Localização da área de pesquisa

Nesta região de estudo destacam-se os rios Marapanim, Maracanã, Ouricuri, Caeté e Jenipaú-Mirim. Os principais divisores das bacias hidrográficas dos rios referendados drenam para o oceano Atlântico, ao norte, assim como para a margem direita do rio Guamá (fora da área de pesquisa), ao sul.

O pacote sedimentar presente comporta principalmente rochas associados ao Grupo Barreiras e a Formação Pirabas, ambos do Cenozóico. Essas unidades litoestratigráficas encerram estratégicas reservas de águas subterrâneas, as quais são utilizadas principalmente na indústria, agricultura, pecuária e abastecimento público de povoados e sedes municipais. 
A cartografia hidrogeológica da geometria e da dinâmica da interligação das águas subterrâneas com as águas superficiais representam temas não só acadêmico como, também, instrumentos de gestão e proteção deste bem mineral. Desta forma, cartografar a geometria das bacias hidrogeológicas é assunto relevante como ferramenta de proteção das águas subterrâneas, assim como para as geociências em geral.

As bacias hidrogeológicas têm como limites as áreas de recarga e descarga de um sistema aquífero. Define-se área de recarga como aquelas em que esses sistemas são realimentados, através de irrigação ou precipitações. A área de descarga é aquela onde a água subterrânea aflora novamente à superfície.

Normalmente, estas bacias hidrogeológicas não acompanham elementos geográficos do terreno, ultrapassando divisores topográficos e configurações de bacias hidrográficas. Desta maneira, a definição das áreas de recarga e descarga da bacia hidrogeológica é bastante complexa, estando condicionada eventualmente a variações litológicas, a condicionantes estruturais tectônicos, a configuração de antigas superfícies de rochas cristalinas ou a presença de rochas cársticas.

Neste contexto, o presente estudo objetivou estabelecer a configuração cartográfica das bacias hidrogeológicas, utilizando os métodos potenciométrico e gravimétrico e, analisar as correlações espaciais entre os limites das bacias hidrográficas e das bacias hidrogeológicas, associadas ao aquífero livre Barreiras, no nordeste do Estado do Pará. Além disso, pretendeuse disponibilizar informações como ferramenta de proteção e gestão das águas subterrâneas rasas, associadas ao aquífero livre Barreiras.

Esse estudo foi desenvolvido pelo Serviço Geológico do Brasil - CPRM, através do Projeto Sistema de Informações de Águas Subterrâneas - SIAGAS, em parceria com a Universidade Federal do Pará - Instituto de Geociências, envolvendo o Programa de Mestrado Profissional em Recursos Hídricos - PPRH, tendo como fundamento o Termo de Cooperação entre as instituições, no momento em tramitação processual, bem como o Plano de Trabalho específico a essa finalidade. 


\section{2 - ASPECTOS FISIOGRÁFICOS}

\section{1 - Geologia regional}

A área de pesquisa está inserida no contexto geológico das Coberturas Cenozóicas composta por Sedimentos Recentes, Pós-Barreiras, Grupo Barreiras e a Formação Pirabas, amplamente distribuídos em toda a região de estudo.

Os Sedimentos Recentes possuem composição argilosa de coloração cinza esbranquiçada, siltes, com leves manchas avermelhadas e amareladas devido à oxidação de ferro, argilas aluvionares e areno-argilosa de coloração amarela. São classificados em aluvionares, coluvionares e volumes intemperados de rochas pré-existentes os quais ocupam as áreas elevadas e suavemente onduladas.

A Formação Pós-Barreiras é representada, predominantemente, por sedimentos inconsolidados e arenosos alaranjados, amarelados a brancos, formados pela desestruturação do Grupo Barreiras.

O Grupo Barreiras é constituído por uma cobertura sedimentar continental, depositada por sistemas fluviais entrelaçados, associados a leques aluviais, planícies de areia, planícies de lama, sendo provável a influência de marés (Rossetti et al, 1989).

A Formação Pirabas é formada por rochas carbonáticas, arenitos calcíferos, marga, folhelhos cinza esverdeados contendo fósseis, na unidade superior e caracterizada por arenitos de granulometria fina a grossa, associados a pelitos, na unidade inferior.

\section{2 - Clima, hidrografia, geomorfologia e solos}

O clima predominante no contexto da área de pesquisa é do tipo Am (Tropical Úmido e Monções), segundo a classificação de Köppen, mais precisamente o subtipo Amw. É caracterizado por ser quente e úmido, com período seco entre os meses de julho a novembro e uma estação chuvosa nos demais meses do ano. De acordo com Costa et al. (1977), as precipitações atingem a média de $2.500 / \mathrm{mm} /$ ano.

A hidrografia compreende as bacias dos rios Guamá, Capim, Maracanã, Quatipuru, Caeté, Piriá e Marapanim. Localizam-se diversos núcleos populacionais às margens desses rios. 
No que se refere aos aspectos geomorfológicos, podem ser observadas paisagens totalmente planas até relevos ondulados, com características morfológicas distintas, denominadas de planície Alúvio-coluvionares, Zonas de Platôs, Pediplano e Relevo Residual. As Planícies Alúvio-coluvionares são compostas de sedimentos inconsolidados que representam as aluviões e coluviões, desenvolvidos ao longo de alguns cursos d'água e/ou zonas de mangue, representadas por uma área baixa e pantanosa, com influência de marés. As cotas estão entre 50 e 100 metros.

$\mathrm{Na}$ área, predominam os seguintes tipos pedológicos: Latossolo Amarelo - formado, predominantemente, a partir dos sedimentos do Grupo Barreiras e dos sedimentos PósBarreiras, em relevo plano a suavemente ondulado. Concrecionário Laterítico - são solos profundos, formados por uma mistura de grãos finos e concreções de arenitos ferruginosos, ocupando, predominantemente, o horizonte "B", associados ao podzólico vermelho-amarelo em terreno suave a ondulado do Terciário. Podzólico Vermelho amarelo - são solos formados a partir da sedimentação terciária, em relevo suave, ondulado, com cobertura de floresta densa. Plintos solo - são solos bastante desgastados, pouco permeáveis e com drenagem moderada e baixa. São encontrados sob uma cobertura vegetal de floresta, savana ou campo, em relevo plano. Areias Quartzosas - são solos formados a partir de sedimentos quaternários, em relevo plano, vegetação de floresta densa e savana. Solos de Mangue - são constituídos por sedimentos não consolidados, recentes, formados por material fino misturado com matéria orgânica. Ocorrem em relevo plano, com pouca drenagem.

\section{3 - HIDROGEOLOGIA REGIONAL}

Na região nordeste do Pará, os sistemas aquíferos são constituídos por Sedimentos Recentes e do Pós-Barreiras, assim como por litotipos do Grupo Barreiras e da Formação Pirabas.

Os Sedimentos Recentes e do Pós-Barreiras constituem aquíferos livres, com espessuras que atingem até um pouco mais de 20 metros. As suas características hidrodinâmicas indicam capacidade específica de $2,4 \mathrm{~m}^{3} / \mathrm{h} / \mathrm{m}$ com 8 horas de bombeamento contínuo, para um poço que capta um aquífero de 7 a $16 \mathrm{~m}$ de profundidade. 
Esses aquíferos apresentam elevada tendência à contaminação, principalmente por agrotóxicos e fertilizantes, nas áreas rurais, e por postos de combustível, fossas, efluentes domésticos e industriais, em zonas urbanas, devido sua composição litológica e a sua proximidade da superfície, potencializados pela alta pluviosidade regional (SEICOM, 1995 apud Araújo, P. P., 2001).

No Grupo Barreiras, ocorrem aquíferos livres e confinados compostos por arenitos conglomeráticos e quartzosas, com camadas argilosas. Intercalados aos arenitos e argilitos encontram-se delgados leitos lateríticos. As camadas arenosas acham-se intercalados de maneira irregular com camadas argilosas, constituindo aquíferos com espessura e distribuição espacial bastante variada. Os leitos lateríticos podem apresentar cavidades interconectadas, constituindo aquíferos com elevadas transmissividades. O nível estático dos aquíferos do Grupo Barreiras varia de 0,80 até 24 metros. Poços captando águas desses aquíferos apresentam capacidade específica de $02 \mathrm{~m}^{3} / \mathrm{h} / \mathrm{m}$, para um tempo de bombeamento de 4 a 8 horas e até $17 \mathrm{~m}^{3} / \mathrm{h} / \mathrm{m}$ para 24 horas de bombeamento (SEICOM, 1995 apud Araújo, P.P, 2001).

Os aquíferos livres ou confinados da Formação Pirabas são compostos por arenitos de origem marinha, intercalados por camadas de argilitos. Esses aquíferos livres apresentam características hidrodinâmicas distintas, bem como espessuras e profundidades variadas. São representados por camadas de arenitos de granulação variando de fina a grossa, com seixos arredondados e subarredondados de quartzo. Esse aquífero, quando do tipo livre, aflora na cidade de Capanema e arredores, assim como em alguns pontos localizados na região costeira de Salinópolis. No restante da área de estudo o aquífero Pirabas, do tipo confinado, está posicionado entre 10 e 70 metros de profundidade, com relação ao nível do mar.

Essas camadas aquíferas, quando confinadas, são separadas por argilitos, folhelhos e margas, razão pela qual são naturalmente pouco susceptíveis à contaminação de origem química e/ou biológica. 


\section{4 - MATERIAL E MÉTODO}

\subsection{Considerações preliminares}

O banco de dados que sustenta essa pesquisa teve como base o cadastramento de aproximadamente 700 poços, efetivado pelo Serviço Geológico do Brasil (CPRM), através do Projeto Sistema de Informação de Águas Subterrâneas - SIAGAS. Para a elaboração do mapa potenciométrico foram selecionados 576 poços, com dados de cotas topográficas, medidas de nível estático, litologia e profundidade do poço.

A falta de dados sobre o perfil dos poços dificulta a caracterização do aquífero. Para efeito de desenvolvimento do trabalho, considerou-se que todos os poços estejam captam águas do aquífero do tipo livre, associado ao Grupo Barreiras, principal foco do presente trabalho.

De acordo com Winter et al. (2003) o mapeamento de bacias hidrogeológicas apresenta diversas limitações, destacando a geodiversidade do meio subterrâneo, as diferentes características da superfície potenciométrica, em função das variações climáticas sazonais e de serem, normalmente, discordantes da superfície topográfica do terreno. Neste trabalho, os limites das bacias hidrogeológicas foram estabelecidos pelo método direto, através da potenciometria e auxílio de elementos estruturais, tais como, lineamentos morfotectônicos observados durante a análise da rede de drenagem e, pelo método indireto, utilizando-se dados geofísicos de gravimetria.

Para o conhecimento da topografia do cristalino foram utilizados dados gravimétricos extraídos do trabalho elaborado pela CPRM, intitulado "Geologia e Recursos Minerais do Estado do Pará (2008)".

\section{2 - Cartografia das bacias hidrogeológicas}

O cartograma das bacias hidrogeológicas é constituído pela interpretação de dois mapas: potenciométrico e o gravimétrico. No primeiro mapa, constam linhas isopotenciométricas obtidas pela resultante da diferença entre a cota dos poços e a profundidade do nível estático.

No segundo mapa, está representada a configuração da superfície do cristalino, numa escala gradativas de cores onde, o vermelho significa menores profundidades com relação à superfície do terreno e o azul as maiores espessuras dos sedimentos sotopostos ao embasamento. 
Esses dados foram interpolados pelo método da Krigagem ordinária, através do Software SURFER, versão 10.0.

A simbologia cartográfica, para a delimitação das bacias hidrogeológicas e hidrográficas, está de acordo com a proposta de Arraes (2007). Nesta proposta metodológica as linhas contínuas, azul-claro, representam os divisores das bacias hidrográficas e aquelas linhas pontilhadas, azul-escuro, são utilizadas para a demarcação dos limites das bacias hidrogeológicas. Estas últimas, quando vazias correspondem a divisores inferidos. As setas indicam os sentidos de fluxo das águas estudadas.

$\mathrm{Na}$ metodologia de elaboração do mapa cartográfico das bacias hidrogeológicas, em essência, procurou-se observar o sentido preferencial de fluxo das aguas subterrâneas, assim como a configuração da superfície do cristalino, fazendo-se constar informações praticas sem comprometer a representação cartográfica. Para tal, utilizou-se o Software ARCGIS versão 10.3 .

\section{5 - RESULTADOS ALCANÇADOS}

Os resultados obtidos da correlação entre o mapa potenciométrico e o mapa gravimétrico, mostram a posição dos divisores hidrogeológicos do aquífero livre Barreiras e o sentido preferencial do fluxo das águas subterrâneas rasas. Observou-se que estas águas apresentam sentido concordante com a direção do escoamento da rede hidrográfica, com exceção de duas áreas pequenas ( $\mathrm{A}$ e B), demarcadas em vermelho no mapa de bacias hidrogeológicas (Figura 2). Nas duas áreas, o sentido de fluxo da água subterrânea rasa não acompanha gradiente topográfico da superfície do terreno, ultrapassando os divisores topográficos e os limites geográficos das bacias hidrográficas, dos rios Ouricuri e Caeté, respectivamente. Neste caso, a hipótese mais provável é que esta discordância esteja relacionada a fatores naturais do meio ambiente subterrâneo, como as variações litológicas, condicionantes estruturais neotectônicos, ou a presença de rochas cársticas próximas à superfície do terreno.

A água que infiltra no terreno da área "A", entre os divisores superficial e subterrâneo, mantém a rede de drenagem perene dos rios Marapanim e Tauá. O mesmo é observado na área "B", onde as águas que penetram no terreno delimitado entre os divisores das bacias dos rios Caeté e Ouricuri contribuem para o fluxo de base que alimenta a recarga das bacias. 


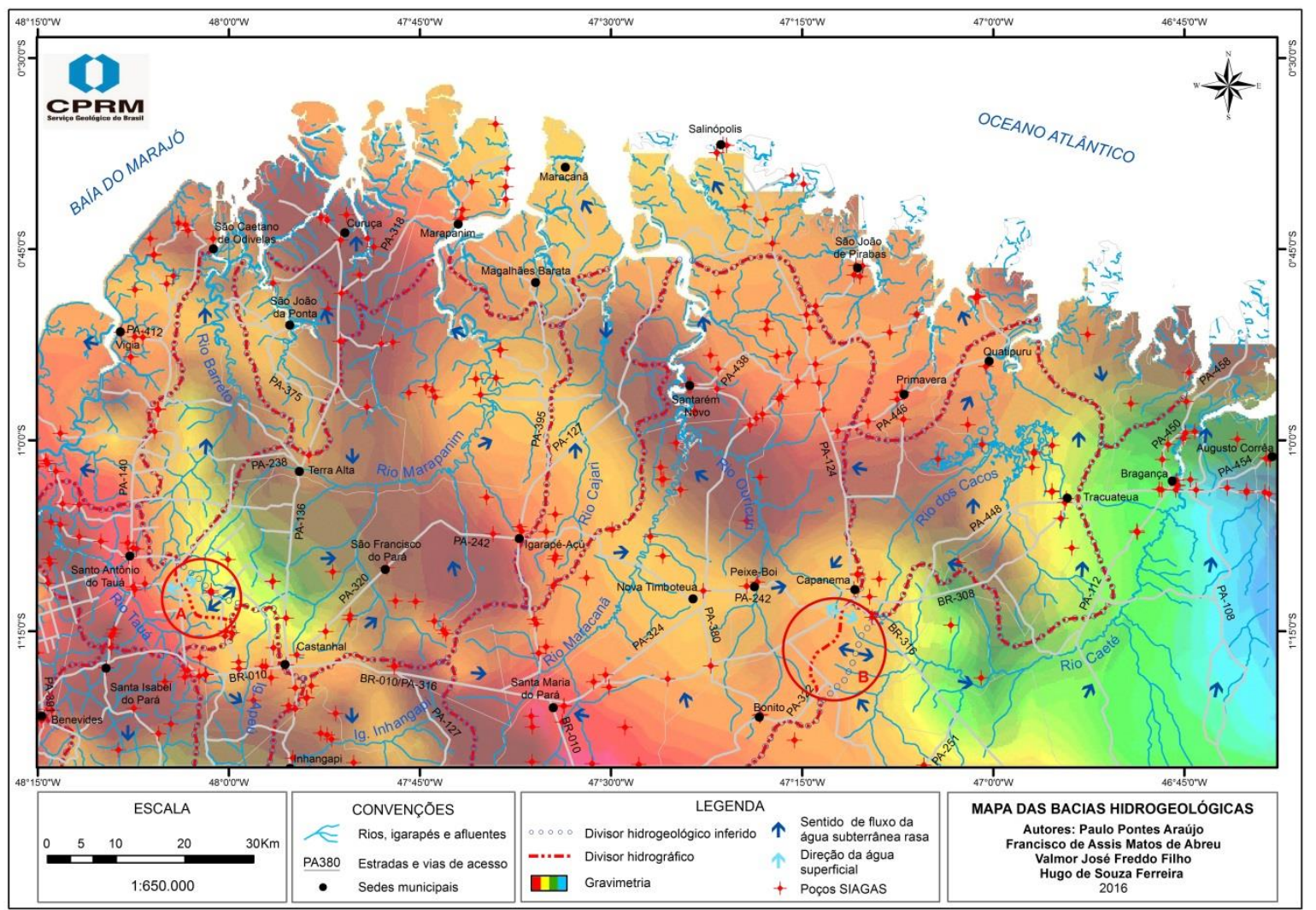

Figura 2. Mapa de bacias hidrogeológicas e sentido de fluxo das águas subterrâneas rasas. Nos círculos vermelhos ("A" e "B"), destacam-se as áreas onde ocorrem discordâncias entre os divisores da bacia hidrográfica e da bacia hidrogeológica.

\section{6 - CONCLUSÕES E RECOMENDAÇÕES}

Da correlação estabelecida entre os mapas com os divisores de bacias hidrográficas e hidrogeológicas no nordeste do Pará pode-se extrair o seguinte:

a) Há no geral uma coincidência entre esses limites, no que tange ao aquífero raso Barreiras, á exceção das áreas "A" e "B” demarcadas no mapa;

b) Tais anomalias podem ser explicadas isolada ou conjuntamente por variações litológicas, condicionantes estruturais neotectônicos, ou a presença de rochas cársticas próximas à superfície do terreno;

c) As informações resultantes deste trabalho são importantes para o equacionamento das questões inerentes ao planejamento e gestão do uso e preservação dos recursos hídricos, assim como a elaboração de proposições de uso sustentável das águas superficiais e subterrâneas da região. 
Por essas razões, entende-se que são necessários estudos regionais e de detalhes, para a avaliação dos parâmetros hidráulicos do aquífero Barreiras, assim como sobre o teor de nitrato nas águas subterrâneas rasas, não considerados nesse trabalho.

Essa é também uma proposta que deve ser estendida para os demais sistemas aquíferos da região, tendo em vista a importância estratégica da qual os mesmos se revertem.

Estes estudos, associados a outros na área de hidrogeologia, são básicos para a simulação da modelagem numérica e a geração de dados que possam contribuir para a gestão e planejamento estratégico do uso sustentável dos recursos hídricos, no nordeste do Estado do Pará, com a recomendação de que sejam iniciados na escala de detalhe, nas áreas "A" e "B".

\section{BIBLIOGRAFIA}

ARRAES, T. M. e CAMPOS, J. E. G., 2007. Proposição de critérios para avaliação e delimitação de bacias hidrogeológicas. Revista Brasileira de Geociências, vol. 37, p.81-89, 2007. www.sbgeo.org.br.

COSTA et al., 1977.

GEOLOGIA E RECURSOS MINERAIS DO ESTADO DO PARÁ, 2008.

IBGE, 2914

ROSSETTI et al, 1989

SOFTWARE SURFER versão 9.0

SOFTWARE ARCGIS versão 10.3

SEICOM, 1995 apud Araújo, P.P, 2001

WINTER, T. C. ROSENBERRY, D. O., LABAUGH, J.W., 2003. Where does the groundwater in small watersheds come from Ground Water, watershed issue, vol. 41, p. 9891000 . 